- Workforce planning

- Development of clinical pathways, policies and standard operating procedures; clinical governance

- Practice Education team develop LTV Study day and Competency Framework, ongoing review of clinical knowledge and skills

- Preparation of children and families for transfer from High Dependency Unit to hospice.

Results

- November 2017: Admission of first tracheostomy and ventilated child and family from HDU to unit

- Child resident for 6 months, successful weaning off day time ventilation

- July 2018 : Admission of second tracheostomy ventilated child from HDU to unit

- Child resident 4 months, discharged on weaning programme

- No complications or significant infections acquired by either child

- Saved hospital bed days: 308

- Staff competency increased from $47 \%$ to $93.5 \%$

- Maintained good relationship with families.

Conclusion With robust education and governance, tracheostomy ventilated children can be safely cared for in a hospice environment. Both sets of parents reported the environment had a positive impact on family dynamics and improved children's physical health and emotional well-being.

\section{PATIENT FEEDBACK FOLLOWING THE EMBEDDING OF SPECIALIST PALLIATIVE CARE INTO A REGIONAL INTERSTITIAL LUNG DISEASE CLINIC: A SERVICE EVALUATION}

Ursula Salobir, Julie Harper, Anne-Marie Bourke, lan Forrest, Claire Donaldson, John Simpson. Marie Curie Hospice Newcastle, Royal Victoria Infirmary Newcastle Hospitals NHS Foundation Trust

10.1136/spcare-2020-PCC.172

Background Patients living with Interstitial Lung Disease (ILD) experience multiple symptoms. Specialist Palliative Care (SPC) provided by Marie Curie was embedded into the regional ILD clinic at the Royal Victoria Infirmary, Newcastle upon Tyne in January 2016. Patients are first seen by a respiratory specialist and, if required, offered a same day SPC review.

Aim To evaluate the experience of patients to assess whether embedding SPC into a regional ILD clinic is acceptable to our service users.

Methods A survey was posted retrospectively to all patients who were reviewed by SPC in the ILD clinic between January 2018 and October 2018 and who were still alive at the time of survey (November 2018). Questions focused on previous awareness of SPC, timing of the appointment, perceived outcomes and overall satisfaction.

Results We identified 42 patients, 23 were alive at the time of the survey. We received 13 completed questionnaires (response rate $57 \%$ ). Although $6 / 13$ had an awareness of palliative care, the majority (12/13) had no prior experience of SPC. 10/13 could identify a positive outcome from their SPC review (the remainder left this question blank). All respondents were satisfied with the timing of their SPC assessment; none would have preferred to return for a separate appointment. All would recommend our service to a friend.
Conclusions We conclude that our integrated service is acceptable to our patients. Despite clinician fears that a previously unplanned SPC review could be overwhelming, survey respondents refuted this concern. Just under half of the patients reviewed by SPC in clinic were in their last year of life. Most respondents were not previously known to SPC, meaning that we are not duplicating the work of other teams. Although these conclusions are specific to the Newcastle ILD/ SPC clinic, we present a model which could be replicated.

\section{A SURVEY TO EXPLORE THE EMOTIONAL WELL-BEING AND RESILIENCE OF A HOSPICE VOLUNTEER GROUP}

Nikhil Sanyal, Jo Poultney, Gemma Jones. Coventry Myton Hospice

\subsection{6/spcare-2020-PCC.173}

Purpose Behind every great hospice is a great army of volunteers. Volunteers at the hospice front line are exposed to the grief, pain, distress and joy that comes from working in palliative care. This survey aimed to establish how supported our volunteers felt in facing that emotional challenge. Our pre-survey hypothesis was that volunteers may feel under-supported and distressed by the clinical situations they are exposed to and may require the hospice to introduce a more formalised system of supervision as is offered to trained members of staff.

Methods A survey was designed collaboratively between a Palliative medicine consultant and Clinical Psychologist to be completed anonymously by volunteers within the inpatient unit and reception.

Results In total 17 volunteers responded with a combined total of 135 years of volunteering experience between them. Over half of the responders had initially volunteered because of a personal contact with hospice care (57\%). 100\% stated meeting people (patients, visitors and staff) as their main source of enjoyment. Responders felt the most challenging times were when patients declined visitors so people had to be turned away (22\%), when young patients are admitted $(14 \%)$ or more practical issues i.e. phones not working (14\%). Only one person had experienced a challenging scenario that had left them distressed. Universally this sample of volunteers felt they had someone to talk if they did find a situation challenging. A buddy system is used so they have a co-volunteer to share concerns with or would approach the staff nurse who has nominated responsibility to oversee the volunteers. The overall majority did not feel a more formal route of support was needed.

Implications: This survey, although limited by its small sample size, still proved our preconceptions wrong. Our volunteer body is resilient and the buddy system provides an internal support network that is well utilised.

\section{ELECTRONIC HANDOVER DOCUMENT: ARE WE COMMUNICATING THE RIGHT INFORMATION IN THE RIGHT WAY?}

Lauri Simkiss, Frances Hakkak. Compton Care Wolverhampton

\subsection{6/spcare-2020-PCC.174}

Background At Compton Care specialist palliative inpatient unit, an electronic document is used to handover pertinent information to doctors providing out of hours cover, 